УДК 581.9(574):58.006(045)

\title{
Г.Ф. Прядко
}

\section{ДОПОЛНЕНИЕ К ФЛОРЕ ГОСУДАРСТВЕННОГО НАЦИОНАЛЬНОГО ПАРКА «БУЙРАТАУ» (КАЗАХCТАН)}

В результате анализа конспекта флоры государственного национального природного парка «Буйратау», появившегося в 2011 г., установлено отсутствие в нем 100 видов растений, выявленных нами ранее для этой территории, а 5 видов отсутствуют в списке флоры Центрально-Казахстанского мелкосопочника. Дается перечень этих видов. В результате оценки редкости видов предлагается включить в новое издание Красной книги Казахстана еще 4 вида: Allium shaerocephalon, Caragana leucophloea, Rhinactinidia eremophila, Trinia muricata.

Ключевые слова: флора, национальный парк «Буйратау», Казахстанский мелкосопочник, редкие виды, Красная книга Казахстана.

DOI: $10.35634 / 2412-9518-2021-31-1-27-34$

В 2011 г. в Центральном Казахстане был создан государственный национальный природный парк «Буйратау», куда вошли частично земли Ерейментауского района Акмолинской области (60 тыс. га) и земли Осакаровского района Карагандинской области (29 тыс. га). В основном это территория природных заказников республиканского значения Ерейментауского и Белодымковского или территория, зарезервированная ранее под Ерейментауский государственный заповедник. Это район древних гор, относящийся к территории Казахской складчатой страны. Он как остров окружен узкой кромкой нераспаханной степи и имеет множество как изолированных массивов глыбовых низкогорий, так и скалистых гряд. Горы невысоки от 300 до 600 м (Керегетас, Койтас, Айгыржал, Сарыжал, Акшокы, Сункаркия, Коянды, Каскыртау, Мыншукур, Куншалган) и только гора Акдым резко поднимается до 904 м.

Территория мелкосопочника расположена в основном в зоне степей, в подзонах умеренно засушливых разнотравно-ковыльных степей, с количеством осадков 250 мм в год, и сухих злаководерновинных, типчаково-ковыльных степей, с количеством осадков 200 мм в год, которые южнее сменяются опустыненными полынно-ковыльными степями. Для сухих степей характерен аридный климат, негативные стороны которого сглаживаются сильным расчленением рельефа гор Ерейментау. Здесь множество ущелий, распадков, долин, логов, расположенных на разной высоте. На дне ущелий текут ручьи, есть в горах и родники, и мелкие речки, и озера. Всё это обеспечивает разнообразие экологических условий, которое дополняется пестротой почвенного покрова. Здесь встречается целая гамма почв лугового и засоленного ряда, но преобладают зональные каштановые почвы. По механическому составу почвы в основном щебнистые, каменистые, маломощные. Все эти факторы в различных сочетаниях создали многообразие экологических ниш для многочисленных видов растений и растительных группировок. Как считал Р. В. Камелин [1], в таких природных резервуарах эволюция жизни и образование видов идёт интенсивно и в наши дни.

\section{Материалы и методы исследований}

В 1981-1985 гг. нами проводились полевые исследования в мелкосопочнике Ерейментау (Ерейментауский район Акмолинской обл. и Осакаровский район Карагандинской обл.) по обоснованию Ерейментауского государственного заповедника [2; 3]. В результате было отмечено более 400 видов сосудистых растений. Собранные гербарные материалы хранятся в Гербарии Ботанического института им. В.Л. Комарова РАН (LE) и были определены преимущественно специалистами этого института, среди которых В.П. Бочанцев, Л.И. Васильева, В.И. Грубов, Т.В. Егорова, С.С. Иконников, Р.В. Камелин, Г.Ю. Конечная, А.А. Коробков, С.Ю. Липшиц, Г.И. Родионенко, Н.Н. Цвелев. Латинские названия растений в ниже приведенном списке даны по сводке С.К. Черепанова [4].

\section{Результаты и их обсуждение}

Горы Ерейментау расположены в Центрально-Казахстанском мелкосопочнике. Его флора была исследована 3. В. Карамышевой и Е. И. Рачковской [5]. Ими выявлено 1453 вида, однако полевыми 
обследованиями были охвачены не все горные массивы, в том числе не был исследован и район гор Ерейментау.

В 2014 г. появился Конспект флоры национального парка «Буйратау» [6], который включает 498 видов. Нами был проведен сравнительный анализ его со списком, полученным нами при полевых исследованиях. В результате сравнения списков было установлено, что в нашем списке есть 100 видов, отсутствующих в работе А.Н. Куприянова с соавторами [6]. Вероятно, проведенные исследования флоры национального парка носили фрагментарный характер и проводились не во все сезоны. Поэтому список растений национального парка, в том числе и редких, приведённый в Конспекте флоры, требует уточнения и дополнения. В связи с этим мы сочли уместным опубликовать список видов, отсутствующих в работе А. Н. Куприянова с соавторами [6]. Все сборы проведены в Горах Ерейментау, поэтому в перечне местонахождений ниже данная ссылка опущена.

\section{Cem. Polypodiaceae R. Br.}

1. Athyrium filix-femina (L.) Roth. Глубокое ущелье хребта Каскыртау, в лесу у ручья, 17.09.1981.

\section{Cем. Poaceae Juss.}

2. Alopecurus pratensis L. 2,5 км к Ю3 от зимовки Ельтай, горное ущелье, 17.05.1981; хр. Каскыртау, влажный луг, 19.05.1983; у р. Баймен, влажный луг, 08.06.1983.

3. Elytrigia lolioides (Kar. et Kir.) Nevsk. Гряды Алтынтау, окр. пос. Алгабас, горная долина, луг, 18.06.1983.

4. Hierochloë repens (Host) Beauv. Зимовка Еликты, межсопочное понижение, сырой луг, 17.05.1981; на границе Карагандинской обл., у березово-осинового колка, 5.06.1982; окр. г. Акдым, влажный луг, 19.05.1983. В работе А.Н. Куприянова с соавторами [6] приведен вид Hierochloë odorata (L.) Beauv., возможно, они принимают этот вид в широком смысле и включают в него H. repens.

5. Leymus akmolinensis (Drob.) Tzvel. Берег р. Оленты, степь вдоль реки, 13.06.1981; г. Акдым, степь, солончак, 19.06.1983; окр. пос. Алгабас, влажный солончаковый луг, 03.07.1983.

6. Leymus multicaulis (Kar. et Kir.) Tzvel. Вблизи зимовки Дюсембулак, у ручья, 04.06.1982.

7. Leymus racemosus (Lam.) Tzvel. (L. giganteus (Vahl) Pilg.). Гора Куншалган, луг у родника, 02.07.1983.

8. Puccinellia doliholepis V. Krecz. Вблизи солёного озера Коржункуль, летнее пастбище Барсан, сырой луг, 23.06.1983.

9. Puccinellia gigantea (Grossh.) Grossh. У плотины на p. Кара-Агаш, у летнего стойбища, 03.07.1983.

10. Stipa korshinskyi Roshev. У зимовки Казымбет, склоны гор, 13.06.1981.

11. Stipa orientalis Trin. Горная гряда Сункаркия, сухие щебнистые склоны, 23.06.1983.

12. Stipa sareptana A. К. Becker. У зимовки Казымбет, степь предгорий, 13.06.1981; гряда Сункаркия, степь, 23.06.1983; у гор Койтас, восточная окраина пос. Алгабас, на распашке, 21.07.1983.

13. Stipa tirsa Steven. Горы Койтас, гряда Мыншукур, предгорье, щебнистые почвы, 03.07.1983; восточная окраина пос. Алгабас, степь, 21.07.1983.

\section{Сем. Cyperaceae Juss.}

14. Eleocharis uniglumis (Link) Schult. Окр. оз. Коржункуль, 5 км восточнее зимовки Мейрман, влажные солончаки, 12.06.1981; окр. пос. Алгабас, у ручья, 13.06.1983.

Ceм. Juncaceae Juss.

15. Juncus atratus Krock. У окраины с. Белодымка, влажный луг, 19.06.1983.

\section{Сем. Alliaceae J. Agardh.}

16. Allium angulosum L. Окр. пос. Алгабас, луг горной долины, 03.07.1983.

17. Allium pallasii Murr. Окр. оз. Коржункуль, 5 км восточнее зимовки Мейрман, щебнистые склоны сопок, 12.06.1981; западнее пос. Алгабас, склоны, 18.06.1983; окр. г. Люлинской, сухие степные склоны, 22.06.1983.

18. Allium sphaerocephalon L. Xp. Каскыртау, ущелье, 15.06.1983 [7].

19. Allium tulipifolium Ledeb. Гряда Мыншукур, у зимовки Жортан, склоны гор, 16.05.1981.

\section{Cем. Liliaceae Juss.}

20. Gagea pusilla (F.W. Schmidt) Schult. et Schult. f. На склонах хр. Каскыртау, 24.04.1983.

\section{Cем. Iridaceae Juss.}

21. Iris sibirica L. Хр. Каскыртау, у зимовки Шайшкуль, ущелье, луговые почвы, 12.06.1981. 
Cem. Santalaceae R. Br.

22. Thesium ramosum Hayne (T. arvense Horvatovszky). Р. Кара-Агаш, у плотины на сопке, 12.06.1981; окр. г. Акдым, предгорье, 19.05.1983; хр. Каскыртау, щебнистые склоны, 17.06.1983.

\section{Сем. Polygonaceae Juss.}

23. Atraphaxis decipiens Jaub. et Spach. Гряда Бозашкыртау, каменистая сопка, 07.07.1983.

24. Persicaria amphibia (L.) S.F. Gray. 1 км восточнее зимовки Карабай, на солончаковом лугу, 07.08.1981.

25. Rumex thyrsiflorus Fingerh. Карагандинская обл., Осакаровский р-н, окр. с. Арнек, у ручья, луг, 22.06.1983. В работе А. Н. Куприянова с соавторами [6] приведен близкий вид R. acetosa L., но скорее всего, это неправильное определение, так как в книге 3. В. Карамышевой и Е. И. Рачковской [5] указано, что Rumex thyrsiflorus - один из наиболее широко распространенных видов рода.

\section{Cem. Chenopodiaceae Vent.}

26. Atriplex prostrata Boucher ex DC. Вблизи с. Белодымка, понижение в степи, влажный солончаковый луг, 27.07.1982.

27. Camphorosma monspeliaca L. Берег солёного озера Коржункуль, сухая степь, 23.06.1983; оз. Майколь, на берегу, 04.07.1983.

28. Halocnemum strobilaceum (Pall.) Bieb. Окр. оз. Коржункуль, у зимовки Мейрман, на берегу солёного озера, 17.09.1981.

29. Halogeton glomeratus C.А. Меу. Окр. оз. Коржункуль, у зимовки Мейрман, берег солёного озера, солончаки, 17.09.1981; там же, 25.09.1983.

30. Krascheninnikovia ceratoides (L.) Gueldenst. (Ceratoides latens (J.F. Gmel.) Reveal et Holmgren). Г. Тюре, каменистая вершина, 04.07.1983.

31. Kalidium foliatum (Pall.) Moq. Окр. оз. Коржункуль, у зимовки Мейрман, на берегу солёного озера, 17.09.1981.

32. Suaeda corniculata (C.A. Mey.) Bunge. Оз. Коржункуль, на берегу, 18.09.1981.

33. Suaeda heterophylla (Kar. et Kir.) Bunge. Берег солёного озера Коржункуль, солончаки, 07.08.1981.

\section{Ceм. Caryophyllaceae Juss.}

34. Dianthus andrzejowskianus (Zapal.) Kulcz. Гора Люлинская, каменистые склоны, 22.06.1983.

35. Dianthus leptopetalus Willd. Ур. Кара-Агаш, сухие пологие склоны, 03.07.1983.

36. Dianthus soongoricus Schischk. Хр. Каскыртау, 5 км юго-западнее зимовки Шайшкуль, каменистая вершина сопки, 08.07.1981; окр. г. Акдым, лесная поляна, 23.07.1983.

\section{Cem. Ranunculaceae Juss.}

37. Adonis vernalis L. Склоны хр. Каскыртау, 25.05.1982.

38. Adonis wolgensis Stev. Хр. Каскыртау, в ущелье и на склонах, 30.04.1982.

39. Pulsatilla flavescens (Zucc.) Juz. Окр. оз. Коржункуль, летнее пастбище Барсан, равнина среди гор, степь, 09.07.1981. Возможно, в своей работе А. Н. Куприянов с соавторами [6] включили этот вид в состав P. patens (L.) Mill., рассматривая его в широком смысле.

\section{Сем. Brassicaceae Buret.}

40. Conringia orientalis (L.) Dum. Окр. г. Акдым, на распашке у луга, 19.06.1983.

41. Isatis costata С.А. Меу. Горы Койтас, ущелье, влажный луг, 08.06.1983.

42. Galitzkya spathulata (Steph.) V. Boczantzeva (Berteroa spathulata (Steph.) C.A. Mey.). Хp. Сункаркия, щебнистые склоны, 13.06.1983.

\section{Ceм. Rosaceae Juss.}

43. Comarum palustre L. Окр. г. Акдым, влажный луг у родника, 22.07.1983.

44. Geum urbanum L. Хр. Каскыртау, 2 км юго-западнее зимовки Шайшкуль, ущелье среди гор, 06.06.1982; Карагандинская обл., Осакаровский р-н, окр. с. Арнек, лесной колок, у ручья, 22.06.1983.

45. Potentilla longifolia Willd. ex Schlecht. Окр. оз. Коржункуль, летнее пастбище Барсан, сырой луг, 07.07.1981; окр. пос. Алгабас, предгорная степь, 08.07.1983.

46. Potentilla patula Waldst. et Kit. Хр. Каскыртау, у зимовки Шайшкуль, остепненные луга, 16.05.1981 [7].

47. Potentilla pensylvanica L. Хр. Каратау, каменистая сопка, 08.07.1981; хр. Каскыртау, югозападнее зимовки Шайшкуль, скальная расщелина, 18.06.1983 [7].

48. Rosa glabrifolia C. А. Mey. ex Rupr. Гора Акшокы, в расщелинах скал, 13.08.1981.

49 Rosa cinnamomea L. Гора Акшокы, в расщелинах скал, 18.07.1982. 


\section{Ceм. Fabaceae Lindl.}

50. Astragalus arcuatus Kar. et Kir. Хр. Каскыртау, у зимовки Шайшкуль, склоны гор, 18.05.1981.

51. Astragalus arkalycensis Bunge. Хр. Мыншукур, предгорные остепненные луга. 13.06.1981.

52. Astragalus austriacus Јacq. Гора Орточенская остепненные склоны 06.07.1983.

53. Astragalus buchtormensis Pall. Склоны гор Мыншукур, у зимовки Жортан, 16.05.1981.

54. Astragalus rupifragus Pall. У зимовки Жортан, склоны сопок, 16.05.1981.

55. Astragalus stenoceras С. А. Меу. Вблизи с. Белодымка, остепненные сопки, 13.06.1981.

56. Caragana leucophloea Pojark. Хр. Каскыртау, у зимовки Шайшкуль, склоны гор, 12.06.1981; хр. Сункаркия, сухие склоны, 18.05.1983; Карагандинская обл., Осакаровский р-н, окр. с. Арнек, сухие склоны, 22.06.1983.

57. Vicia tenuifolia Roth. Хр. Кыскыртау, у зимовки Шайшкуль, горное ущелье, 13.06.1981; хр. Каратау, ущелье, 17.06.1983.

\section{Ceм. Geraniaceae Juss.}

58. Geranium pseudosibiricum J. Mayer. Хр. Каскыртау, 4 км юго-западнее зимовки Шайшкуль, лесная опушка у неглубокого ущелья, 08.07.1981; г. Акшокы, у подножия, 07.08.1981; окр. г. Куншалган, природниковый луг, 06. 07. 1983; гр. Мыншукур, в черноольшаннике у ручья, луг, 07.07.1983.

\section{Сем. Linaceae S. F. Gray.}

59. Linum pallescens Bunge. У с. Белодымка, на каменистых почвах, 05.06.1982; окр. пос. Алгабас, предгорная степь, 13.06.1983.

\section{Ceм. Zygophyllaceae R. Br.}

60. Zygophyllum furcatum С. А. Меу. Окр. оз. Коржункуль, вблизи зимовки Мейрман, на берегу солёного озера, 17.09.1981.

Ceм. Lythraceae J. St.-Hil.

61. Lythrum salicaria L. Гора Акшокы, 5 км южнее зим. Дюсембулак, у ручья Карабулак, луг, 07.08.1981; хр. Мыншукур, черноольшанник у ручья, 07.07.1983.

\section{Сем. Umbelliferae Juss.}

62. Ferula varia (Schrenk) Ttrautv. Ущелье, недалеко от летнего пастбища в окр. пос. Алгабас, 03.07.1983.

63. Seseli eriocarpum (Schrenk) B. Fedtsch. (Libanotis eriocarpa Schrenk). Вблизи зимовки Дюсембулак и на окраине пос. Алгабас, склоны гор, 27.07.1983.

\section{Сем. Caprifoliaceae Juss.}

64. Lonicera microphylla Willd. ex Schult. Горы Койтас, расщелины скал, 20.06.1983.

\section{Cем. Limoniaceae Ser.}

65. Limonium caspium (Willd.) Gams. Окр. оз. Коржункуль, вблизи зимовки Мейрман, берег солёного озера, солончаки, 25.09.1983, там же, 08.09.1984.

66. Limonium suffruticosum (L.) O. Kuntze. У солёного озера Коржункуль, вблизи зимовки Мейрман, солончаки, 25.09.1984; у оз. Телембек, солончаковый луг, 28.09.1983.

\section{Сем. Gentianaceae Juss.}

67. Gentiana cruciata L. Гора Акшокы, 5 км южнее зимовки Дюсембулак, щебнистые склоны гор, 07.08.1981; зимовка Шайшкуль, окр. пос. Алгабас, на лесной поляне, 28.07.1982.

\section{Ceм. Asclepiadaceae R. Br.}

68. Vincetoxicum sibiricum (L.) Decne. У зимовки Телембек, склоны сопки у дороги, 17.09.1981.

Сем. Cuscutaceae Dum.

69. Cuscuta lupuliformis Krock. 5 км южнее зимовки Дюсембулак, в осиновом колке, 07.08.1981.

\section{Сем. Boraginaceae Juss.}

70. Argusia sibirica (L.) Dandy (Tournefortia sibirica L.). Окр. оз. Коржункуль, у зимовки Мейрман, на берегу р. Кара-Агаш, 12.06.1981; окр. пос. Алгабас, у лесного колка, 16.06.1983.

\section{Cем. Labiatae Juss.}

71. Nepeta ucranica L. Хр. Каскыртау, остепненные склоны, 06.06.1982; там же, 18.05.1983; окр. гор Койтас, луговая степь, 08.06.1983.

72. Thymus eremita Klok. Хр. Каскыртау, у зимовки. Шайшкуль, расщелины скал. 08.07.1981.

73. Thymus minussinensis Serg. К северу от р. Кара-Агаш, вблизи зимовки Мейрман, вершины каменистых сопок, 13.06.1981. 


\section{Сем. Scrophulariaceae Juss.}

74. Dodartia orientalis L. Гора Акшокы, предгорная степь, 23.06.1983.

75. Linaria dmitrievae Semiotr. Окр. оз. Коржункуль, у летнего пастбища Барсан, 30.06.1981.

76. Linaria ruthenica Blonski. Хр. Каратау, луговая степь, 13.06.1983.

77. Melampyrum cristatum L. У подножья гор Коянды, западнее г. Ерейментау, степь, 28.07.1982.

78. Pedicularis kaufmannii Pinzg. У ручья Кара-Булак, степь вдоль ручья, на щебнистых почвах, 12.06.1981; Соколиные горы, склоны сопок, степь, 17.06.1983; окр. пос. Алгабас, средняя часть склона, 23.06.1983.

79. Rhinanthus songaricus (Sterneck) В. Fedtsch. Окр. оз. Коржункуль, берег речки Карасу, летнее пастбище Барсан, сырой луг, 07.07.1981.

80. Veronica laeta Kar. et Kir. Хр. Мыншукур, окр. оз. Коржункуль, 3 км северо-восточнее зимовки Мейрман, каменистые склоны, 08.08.1981; хр. Каскыртау, склоны гор, 28.07.1982.

Сем. Lentibulariaceae Lindl.

81. Utricularia vulgaris L. Оз. Телескуль, в стоячей воде, 12.06.1981.

\section{Cем. Rubiaceae Juss.}

82. Galium densiflorum Ledeb. var. rosmarinifolium (Bunge) Tzvel. (G. saurense Litv.). Хр. Каскыртау, на склонах, 27.07.1981; там же, степь на склоне, 22.06.1983.

83. Galium palustre L. Восточнее зимовки Каратай, низинный луг у высохшего ручья, 07.08.1981.

84. Galium ruthenicum Willd. Склоны хр. Каскыртау, у зимовки Шайшкуль, склоны гор, щебнистые почвы, 08.07.1981; окр. с. Арнек, степь, 22.06.1983; окр. пос. Алгабас, степь, 08.07.1983.

\section{Ceм. Campanulaceae Juss.}

85. Campanula stevenii Bieb. (C. wolgensis P. Smirn.). Гора Нияз, луговая степь, 05.06.1982; окр. пос. Алгабас, луг, 16.06.1983.

\section{Ceм. Compositae Giseke}

86. Ajania fruticulosa (Ledeb.) Poljak. У речки Кулумбек, солонцеватый луг, 17.09.1981; окр. оз. Коржункуль, зимовка Мейрман, 25.09.1983.

87. Ancathia igniaria (Spreng.) DC. Окр. оз. Коржункуль, 3 км сев.-вост. зимовки Мейрман, степь предгорий, солонцовые почвы, 07.08.1981.

88. Artemisia marschalliana Spreng. Склоны гор Мыншукур, осыпи, 25.09.1983; горы Каскыртау, склоны гор, 25.09.1983. А. Н. Куприянов и др. [6] приводят A. campestris L. и пишут, что это новый вид для Казахстана. Но А. А. Коробков, считает, что это неправильное определение и из этой группы в г. Ерейментау встречается только A. marschalliana.

89. Carduus thoermeri Weinm. Окр. пос. Алгабас, у дороги, 08.07.1983.

90. Centaurea adpressa Ledeb. Окр. оз. Коржункуль, у летнего пастбища Барсан, сырой луг, 07.07.1981.

91. Cirsium alatum (S.G. Gmel.) Bobr. Окр. пос. Алгабас. 0,5 км восточнее зимовки Карабай, сухая степь, щебнистые почвы, 07.08.1981.

92. Galatella tatarica (Less.) Novopokr. (Linosyris tatarica (Less.) C.A. Mey.) Хр. Каскыртау, у зимовки Шайшкуль, каменистые склоны, 13.07.1982.

93. Onopordum acanthium L. Окр. пос. Алгабас, у дороги, 08.07.1983.

94. Rhinactinidia eremophila (Bunge) Botsch. Каменистые почвы склонов гор Алтынтау, Акдым, Жан-Тобе, Койтас, Сункаркия, Каратау [7].

95. Saussurea elegans Ledeb. Низинный луг у зимовки Дюсембулак и окр. оз. Коржункуль, степь среди гор на щебнистых почвах у летнего пастбища Барсан, 23.07.1983.

96. Saussurea laciniata Ledeb. Окр. оз. Коржункуль, у зимовки Мейрман, берег солёного озера, 02.08.1983.

97. Scorzonera purpurea L. Хр. Каскыртау, в окр. пос. Алгабас, луговая степь, 07 и 16.06.1983.

98. Sonchus oleraceus L. Окр. пос. Алгабас, солончаки, 19.08.1982.

99. Tanacetum achilleifolium (Bieb.) Sch. Вip. Окр. оз. Коржункуль, 5 км восточнее зимовки Мейрман, мелкие сопки, малоразвитые почвы, 12.06.1981; хр. Сункаркия, сухие склоны, 28.06.1983.

100. Youngia diversifolia (Ledeb.) Ledeb. (Crepis diversifolia (Ledeb.) B. Fedtsch.) Вершина горы, Айтыржал, небольшая расщелина, 06.07.1983. 
Среди наших сборов оказались интересные находки и для флоры Центрально-Казахстанского мелкосопочника. Это 5 видов растений, которые отсутствуют в работе 3.В. Карамышевой и Е.И. Рачковской [4]: Allium shaerocephalon, Caragana leucophloea, Ferula varia, Galium densiflorum var. rosmarinifolium, Veronica prostrata L.

В приведённом выше списке, есть редкие виды как для флоры национального парка, так и для флоры Центрально-Казахстанского мелкосопочника.

Один из таких редких видов - Rhinactinidia eremophila. Найденное нами на хр. Сункаркия растение В. П. Бочанцев определил как Krylovia eremophila (Bunge) Schischk. ex Tamamsch. Впоследствии этот род был отнесен к роду Rhinactinidia [8]. В следующем году, который выдался сухим и холодным, мы его не нашли, хотя тщательно осмотрели место его прежней находки. Были обследованы и другие участки этого хребта. На третий год, когда весна была теплой и влажной, поиски были возобновлены и в результате выявлены десятки экземпляров растений. В этот год вид был найден и на других горных хребтах: Алтынтау, Каратау, Койтас, Жан-Тобе, Акдым, на бедном каменистом субстрате склонов северной экспозиции. Чаще нами обнаруживались лишь небольшие группы растений этого вида до двух десятков особей. Во всех местах преобладали старовозрастные особи. Этот факт, как и неспособность Rhinactinidia отрастать в неблагоприятные годы, указывает на угасание популяции.

Л.И. Малышев и Г.А. Пешкова [9] нашли этот вид в Казахстане в районе озера Балхаш и на горе Актау в южной части Акмолинской области. Указанные авторы считают, что встреченные популяции Rhinactinidia eremophila являются фрагментами её некогда обширного ареала, расположенного в Средней Азии, Казахстане и Сибири.

Редкими из найденных нами видами для гор Ерейментау являются: Seseli eriocarpum, Atraphaxis decipiens, Leymus akmolinensis, Krascheninikovia ceratoides. Эти горно-степные и скальные растения произрастают на маломощных почвах и каменистых почвенных субстратах.

Особо отметим единственную находку единственной особи Krascheninnikovia ceratoides. Определил этот вид, как и многие другие, специалист по флоре Казахстана В.П. Бочанцев.

Из видов, занесённых в Красную книгу Казахстана [10], в Ерейментауском мелкосопочнике отмечены следующие: Alnus glutinosa (L.) Gaertn., Adonis vernalis, A. wolgensis и Dianthus andrzejowskianus.

Горные массивы национального парка «Буйратау» являются уникальным заповедным краем и убежищем для редких и исчезающих видов. Уникальный горный массив можно и нужно сохранить как природный резерват редких видов и их сочетаний. Все редкие растения можно было в недавнем прошлом отнести к видам, находящимся под угрозой исчезновения из-за выпаса овец. Многочисленные отары паслись практически по всему горному массиву, кроме верхних склонов, почти лишенных растительности. Создание же государственного национального парка «Буйратау», вероятно, снимет угрозу потерь редких видов растений, если будет соблюдаться ограничение хозяйственной деятельности, особенно выпаса скота.

Предлагаем включить в новое издание Красной книги Казахстана очень редкие виды, встречающиеся в национальном парке «Буйратау»: Allium shaerocephalon, Caragana leucophloea, Rhinactinidia eremophila, Trinia muricata. Эти виды являются редкими не только в Центрально-Казахстанском мелкосопочнике, но и на всей территории Казахстана [11], a Allium shaerocephalon известен только в пределах национального парка «Буйратау».

\section{Заключение}

В результате анализа опубликованного списка флоры государственного национального природного парка «Буйратау» [6] установлено отсутствие в нем 100 видов растений, выявленных нами ранее (1981-1985 гг.) на этой территории. Кроме того, 5 видов, найденных нами, отсутствуют в списке флоры Центрально-Казахстанского мелкосопочника [5]. 4 вида из флоры национального парка «Буйратау», наиболее редкие на всей территории Казахстана, предлагается включить в новое издание Красной книги Казахстана.

\section{Благодарности}

Приношу большую благодарность сотрудникам отдела Гербарий высших растений Ботанического института им. В. Л. Комарова РАН, принимавшим участие в определении собранного нами гербария, а также член-корреспонденту Р. В. Камелину и кандидату биологических наук Г.Ю. Конечной за помощь в подготовке текста данной статьи. 


\section{СПИСОК ЛИТЕРАТУРЫ}

1. Камелин Р.В. О некоторых замечательных аномалиях во флоре горной среднеазиатской провинции // Бот. журн. 1967. Т. 52, № 4. С. 447-461.

2. Прядко Г.Ф., Пяхина А.К., Баньковский Л.В. Редкие растения гор Ерментау, рекомендуемые для заповедной охраны // Изв. АН Каз. ССР. Сер. Биол. 1983. № 3. С. 64-66.

3. Прядко Г.Ф. Ерментау. Алма-Ата: Кайнар, 1987. 171 с.

4. Черепанов С.К. Сосудистые растения России и сопредельных государств. СПб.: Мир и семья-95, 1995.992 с.

5. Карамышева 3.В., Рачковская Е.И. Ботаническая география степной части центрального Казахстана. Л.: Наука, 1973. 278 с.

6. Куприянов И.А., Хрусталёва И.А., Габдуллин Е.М., Исмаилова Ф.М. Конспект флоры государственного национального парка Буйратау (горы Ерментау, Центральный Казахстан) // Ботан. исслед. Сибири и Казахстана. 2014. № 20. С. 30-57.

7. Прядко Г.Ф. О некоторых реликтовых и новых для флоры Казахстана видах // Бот. журн. 1987. Т. 72 , № 11. C. $1550-1552$.

8. Бочанцев В.П. О роде Rhinactinidia Novopork // Новости сист. высш. раст. 1986. Т. 23. С. 180.

9. Малышев Л.И., Пешкова Г.А. Нуждаются в охране. Новосибирск: Наука, 1979. 176 с.

10. Красная книга Казахстана. Алма-Ата: Багира ЛТД, 2006. 550 с.

11. Флора Казахстана. Алма-Ата, 1956-1966. Т. 1-9.

Поступила в редакцию 12.01.2021

Прядко Галина Филипповна, кандидат биологических наук, доцент

ФГБОУ ВО «Новгородский государственный университет им. Ярослава Мудрого»

173003, Россия, г. Великий Новгород, ул. Большая Санкт-Петербургская, 41

E-mail: galina_pryadka@mail.ru

\section{G.F. Pryadko}

\section{ADDITION TO THE FLORA OF THE STATE NATIONAL PARK "BUIRATAU"}

DOI: $10.35634 / 2412-9518-2021-31-1-27-34$

As a result of analysis of the flora prospectus of the state national park "Buiratau", which appeared in 2011, the absence of 100 plant species identified earlier by us for this area was determined, and 5 species are absent from the list of flora of the Central Kazakhstan uplands (melkosopochnik). A list of these species is given. As a result of the assessment of the rarity of species, it is proposed to include 4 more species in the new edition of the Red Book of Kazakhstan: Allium shaerocephalon, Caragana leucophloea, Rhinactinidia eremophila, Trinia muricata.

Keyword: flora, national park Buiratau, rare species, Kazakhstan uplands, Red Book of Kazakhstan.

\section{REFERENCES}

1. Kamelin R.V. [About some remarkable anomalies in the flora of the mountainous Central Asian provintsii], in Botanicheskii Zhurnal, 1967, vol. 52, no. 4, pp. 447-461 (In Russ.)

2. Pryadko G.F., Piahina A.K., Bankovskii L.V. [Rare plants Yermentay Mountains that are recommended for the protection of the reserve], in Izvestiya Akademii Nauk Kazakhskoy SSR. Seriya biologicheskaya, 1983, no. 3, pp. 64-66 (In Russ.)

3. Pryadko G.F. Ermentau [Yermentay], Alma-Ata: Kainar Publ., 1987, 171 p. (In Russ.)

4. Cherepanov S.K. Sosudistye rasteniya Rossii i sopredel'nykh gosudarstv [Plants of Russia and adjacent states], St. Petersburg: Mir i semja-95 Publ., 1995, 992 p. (In Russ.)

5. Karamysheva Z.V., Rachkovskaya E.I. Botanicheskaya geografiya stepnoy chasti tsentral'nogo Kazakhstana [Botanical geography of steppe part of central Kazakhstan], Leningrad: Nauka Publ., 1973, 277 p. (In Russ.)

6. Kupriyanov A.N., Khrustaleva I.A., Gabdullin E.M., Ismailova F.M. [Synopsis of the flora of the state national park Buiratay (Mountain Jermentay, Central Kazakhstan)], in Botanicheskiye issledovaniya Sibiri i Kazakhstana [Botanical investigations of Siberia and Kazakhstan], 2014, no. 20, pp. 30-57 (In Russ.)

7. Pryadko G.F. [Some relict flora and new kinds of Kazakhstan], in Botanicheskii Zhurnal, 1987, vol. 72, no. 11, pp.1550-1552 (In Russ.)

8. Bochantsev V.P. [About the genus Rhinactinidia Novopork.], in Novosti sistematiki vysshikh rasteniy, 1986, vol. 23, p. 180 (In Russ.) 
9. Malyshev L.I., Peshkova G.A. Nuzhdayutsya v okhrane [Need protection], Novosibirsk: Nauka Publ., 1979. 176 p. (In Russ.)

10. Krasnaya kniga Kazakhstana [Red data book of Kazakhstan], Alma-Ata: Bagira LTD Publ., 2006. 550 p. (In Russ.)

11. Flora Kazakhstana [Flora of Kazakhstan], Alma-Ata, 1956-1966, vol. 1-9 (In Russ.)

Pryadko G.F., Candidate of Biology, Associate Professor

Yaroslav-the-Wise Novgorod State University

Bolshaya Sankt-Peterburgskaya st., 41, Veliky Novgorod, Russia, 173003

E-mail: galina_pryadka@mail.ru 